providing an elected representative on the district management team to promote the particular interest of each sector. The local administrative, financial, and nursing representatives complete the team to provide a balanced executive group. If the new system of health districts has this team at its helm, able to make executive decisions and answerable directly to the regional health authority, the system will work. The simple recipe for success must be that the district management team needs to be given its budget and then be master of its own destiny.

The area administrative system of the 1974 reorganisation has been a disaster for several reasons other than the obvious one of introducing a grey area of non-decision into the system. In my view one of the important reasons for the failure of area administration has been that it rests the representation of the medical profession on the shoulders of a single doctor. This single doctor, usually a community physician, is the sole medical representation on the area health authority's crucial executive committee, the area team of officers. I intend no criticism of community physicians here. It is simply that a community physician cannot be sufficiently familiar with the special problems of general or hospital practice any more than I, a consultant surgeon, can give sensible advice on a community psychiatric service. It is essential to retain the tripartite medical representation on the health district's executive committee to produce a balanced medical advice input.

I would urge the profession to do two things. (1) Be prepared to be involved in your own administration. It is in your own and your patient's interest because no lay person can or will do it for you properly. So read the Patients First and send your comments to the address given on page 23. (2) Insist that the new district administration's executive committee is the district management team and that its constitution remains the same as it is todaywith doctors who work in hospitals, general practice, and community medicine working together for the good of our patients-patients first.

RICHARD G NOTLEY

Farnham Road Hospital,
Guildford, Surrey GU2 5LX

SIR,-The emphasis on maximum delegation in the section on management in the hospital and in the community services referred to in the DHSS consultative paper Patients First is likely to be generally welcomed. It does not, however, go far enough. The treatment of patients in hospital takes place at ward level by a team headed by the consultant. The management of the whole ward, in which there are usually several consultant teams, is the responsibility of the sister or charge nurse; and staff providing support services in the ward should be made explicitly accountable to the sister in charge.

The proposal in paragraph 12(c) that "staff working within hospitals in non-clinical support functions should be accountable to the hospital administrator rather than to district level managers" will help, but the care of the patient will be greatly enhanced if the ward sister is officially made the local manager of the domestics and porters while they are working in her ward. The present monitoring role of the ward sister is too imprecise and leaves too much to chance.

\section{Where have all the nurses gone?}

SIR,-Nancy Arnold's article "Where have all the nurses gone?" (19 January, p 199) was like a breath of fresh air for those many doctors and few nurses who warned of the consequences of implementing the Salmon Report of 1966 in terms of loss of job satisfaction, recognition, and morale of nurses at the bedside. With the ward sister's essential role undermined subsequent inroads by nurse educators, domestic supervisors, trade union officials, and EEC bureaucrats alike have met little opposition.

Mrs Arnold's article should be made essential reading for all nurse and medical administrators, and a topic for debate by all who enter the nursing profession over the next few years.

J W Paulley

Department of Medicine,

Ipswich Hospital,

SIR,-The article "Where have all the nurses gone ?" by Nancy Arnold (19 January, p 199) in laying the blame for the ills of the nursing profession at the feet of enrolled and auxiliary nurses is in itself a further, albeit small, contribution to the decline of morale of nurses.

Hostility towards enrolled and auxiliary nurses is not limited to directors of nurse education (is this Salmonese for "tutor"?) but is found among many doctors. Their belief in the superiority of registered nurses is largely based on their ignorance of nurse education and should at any rate be quickly dispelled by experience. Enrolled and auxiliary nurses perform most of the basic care on the wards today and are competent. Enmity between groups of workers leads to loss of morale and its perpetuation by senior management must be harmful. Standards must surely be raised by a return to sensible selection of studentsbased not on academic achievement but on say, Ashdown's qualifications for a good nurse $^{1}:(a)$ a real love of attending to the sick and helpless; $(b)$ a strong constitution; and (c) an equable temperament.

Doctors are responsible for much of the decline in nursing. They have forgotten their duty to concern themselves with nurses' welfare. Comradeship between doctors and nurses is less evident. They failed to save nursing from Salmon. They fail now to protect nurses from intimidation and interference by nursing administrators. A renewed relationship between doctors and all working-that is, nonadministrative-nurses would be a start to getting a better and happier nursing profession.

D J TUPper

Southampton General Hospital,

Southampton, Hants

Ashdown AM. A complete system of nursing. London J M Dent, 1922 .

\section{The practice nurse}

SIR,-We have found most interesting the study of Dr W H R Walters and others (12 January, $p$ 87) concerning the work of the practice nurse. One of the things not mentioned was what happens to the extensive amount of paperwork engendered by the work of the practice nurse-for instance, in filling out laboratory forms, in sending off claims to the family practitioner committee, and in documenting important information such as on immunisations.

We noted that over a four-year period there are practice nurses working a total of 68 hours a week and seeing just under 44000 patients and it is not clear whether the secretarial duties were done by the practice receptionists, in which case the total hours involved would be considerably greater than 68 , or whether this work was done by the nurses themselves, in which case they would spend a fair amount of time in non-nursing duties.

Our own practice nurse has managed to see about 45000 patients in the last four years, working only a 40-hour week, with the simple expedient of having her own secretaryreceptionist. I am sure that this is the next step forward in the evolution of the practice nurse, particularly in health centres, where several practices may join together to employ both a practice nurse and her secretaryreceptionist. It takes a tremendous load of work off the other practice ancillary staff and also ensures that the nurse, an expensive item of employment, is fully occupied with skilful nursing duties alone.

Charles ReES

The Health Centre

Ferndown, Dorset BH22 9HB

\section{Domiciliary visits by consultants}

SIR,-While agreeing with some of the remarks of my friend Dr P E Jackson (26 January, p 256), I must state that I to a very large extent deprecate the fall-off in domiciliary visits in our area.

This has happened through no direction of our own and I think arises from various factors such as the expediency of the general practitioner, the fact that patients with dubious chest pain are best rapidly admitted to the coronary care unit, and, finally, the fact that many general practitioners now have their own electrocardiographs.

In the past, when a larger number of domiciliary visits were undertaken the work burden was considerable as it was usually late and out of hours and often involved much travel. However, the opportunity to meet a general practitioner in a patient's home is a privilege that I miss. When one has seen a patient in his or her home the problem of rehabilitation and follow-up is enormously simplified by the knowledge that one has acquired of the doctor, the family, and the environment. In addition, there is usually a mutual exchange of medical ideas, which is profitable and stimulating. In the absence of such meetings, increasingly general practitioners are again to hospital doctors just becoming a name at the bottom of a letter or a voice on the telephone. It does help to be able to put a face and a person to those with whom one is having important dealings.

In contrast with Dr Jackson, I find that general practitioners are not always good at deciding between admission and urgent outpatient appointments. Pulmonary oedema, that most distressing of symptoms, is frequently not diagnosed and treated urgentlythe usual diagnosis is bronchospasm and effective treatment is thereby delayed. Rapid atrial fibrillation even when confirmed by a practice electrocardiogram is often not treated without the blessing of a hospital visit. Both 
these dangerous conditions could be helped by domiciliary visits to discuss effective management.

On the other hand, when these patients do reach the hospital outpatients department the staff can hardly send them away with a serious condition and so admission has to be arranged immediately. A home visit could often have avoided this and given relief earlier. In the frightened patient the domiciliary visit can act as a reassuring bridge between home and hospital even when admission is necessary.

Domiciliary visits are much cheaper than the daily cost of a hospital bed-which is in any case needed for essential patients.

Hugh A Fleming

Regional Cardiac Unit,

Papworth Hospital,

\section{Unemployed doctors}

SIR,-I wish to submit an interim report describing the response to the letter published in the BMF (29 September p 800), asking for information from unemployed doctors.

Twenty-six replies have been received to date. Seventeen respondents were male and fifteen were UK graduates. Nineteen doctor were engaged in long-term or series of shortterm locum appointments and seven were actually unemployed. Most respondents were at SHO grade, a predictable "bottleneck" in view of the already increased number of new graduates, although another common problem was that of the locum consultant who had great difficulty in obtaining a permanent post.

A further report will be submitted later, as I am still receiving replies.

R G WILKIN Honorary Secretary
North-west Regional Hospital Junior Staff Committe

Manchester M14 5RH

\section{Inner city GPs}

SIR,-I am currently a vocational trainee in East London, and complete the scheme in February. I have lived locally for the past seven years, was a clinical student at the local teaching hospital, and have worked in the surrounding hospitals. I am one of the firs batch of trainees to complete this course, which was in part designed to encourage young doctors to stay in the inner city area. I am positively motivated to stay, but unhappily there appear to be few openings, and I am disappointed to have had to move out of the area.

While I think problems such as housing, schooling, and physical environment are important factors in the recruitment of young general practitioners to these areas, I do not believe that they are as important as providing the right kind of practice opportunities. In my area there are the legendary aging singlehanded practitioners working in what would now be considered inadequate premises. There is at present one new health centre devoid of GPs, and another occupied by an elderly GP and an assistant with empty suites. The problem of keeping young GPs in the area is to phase recruitment with retirement, and to provide purpose-built accommodation. The risk is that without such planning and adequate premises the present style of provision will be perpetuated.
Anticipating my current situation two years ago, I submitted a paper to the Area Health Authority medical advisory committee suggesting, firstly, that retiring GPs are offered the services of a young GP at little or no cost on the understanding that they retire in a specified time (for example, two years) and, secondly, purpose-built premises are provided in a planned way. This would lead to an orderly transfer of patient care, benefit the elderly doctor, and offer an attractive opportunity for young GP. The cost of such a scheme would be minimal in comparison with other "inner city projects" and would have a more predictable outcome. I would therefore agree with the recent recommendation from the Working Party on Underdoctored Areas (24 November, p 1382) to introduce a more fiexible initial practice allowance in order to finance such a scheme. I also agree with $\mathrm{Dr}$ John Ball's idea ( $p$ 1383) of a GP co-ordinator whose responsibility it would be to facilitate such developments in each district.

\section{London E3}

J A JEWELL

\section{Women and general practice}

SIR,-I read with surprise the letter from Dr Julie Shepherd (26 January, p 257), who states that the BMA attempts to exclude women from general practice. Perhaps it is the women themselves who do not explore the opportunities open to them. I advertised in the $B M \mathcal{F}$ for a part-time trainee for many weeks-until I felt embarrassed about the repetition-but I had no suitable applicants. The husband of my present trainee saw my notice on a hospital notice board. At least two other practices in this district appoin part-time trainees and both trainers (women) are active members of the BMA.

Elstree, Herts WD6 3RQ

ShIRley E NathaN

\section{Sex distribution of distinction awards}

SIR,-We are glad that Dr Eva Lester (19 January, p 198) has pursued the suspicion we raised in our last two papers on distinction awards. ${ }^{12}$ To put her findings more bluntly than she does, men are more than twice as likely as women to get awards; and men score three times as many award points per cent as women $(\mathrm{A}+=4, \mathrm{~A}=3, \mathrm{~B}=2, \mathrm{C}=1)$. Ye the present generation of women consultants were those girls who had to fight harder than boys to get into medical schools and for whom, as doctors, it was harder to become consultants. It is wildly improbable that the Distinction Awards Advisory Committee has given them a fair allocation.

The chairman of the committee has described his attention to a just and appropriate balance of opinion to be represented in his committees. Dr Lester will not be surprised to learn that, already a minority of one in 10 among consultants, on the advisory committees themselves women appear in a minority of one in 60 .

S BOURNE

Tavistock Clinic,

P BRUGGEN

1 Bourne S, Bruggen P. Br Med f 1978; : $456-8$.
2 Bourne S, Bruggen P. Br Med f 1979; : $638-9$.

\section{A4 records}

SIR,-Along with a small but growing number of practices throughout Britain, we are now changing over to A4 records. One problem which has already been encountered is that of identifying other practices with A4 records when patients' notes are transferred.

The consensus procedure seems to be that when a patient leaves the practice the notes are restored to their original form and stuffed into an EC6 envelope either by the practice staff or by the family practitioner committee. This is clearly untidy, wasteful, and time consuming and it would be nice to be able to identify practices where A4 records would be welcomed. These, I would hope, would include not only those that had already gone over to A4 records or were planning to do so but also those practices which could accommodate dual filing system and would be happy to receive A4 folders on new patients.

My suggestion is that the medical record card FP4 be amended to include a small box labelled "A4 acceptable." This could be placed in a similar position to the existing boxes for milage or drugs and a tick would then signify that the doctor would be willing to accept A4 records.

I have forwarded this suggestion to my local medical committee, but would be most interested to hear whether others may have found alternative solutions to the problem.

F. J BORCHARDT

The Health Centre,
Pershore, Worcs WR10 1DR

\section{Disputes procedure}

SIR,-The attention of my association has been drawn to the article by $\mathrm{Mr}$ Norman Ellis (5 January, p 61) entitled "A panic measure with hidden hazards."

In this article $\mathrm{Mr}$ Ellis is critical of an agreement which he believes the General Whitley Council is about to conclude on a national disputes procedure and sees indeed the danger of health authorities, possibly inadvertently, passing over for decision by arbitration issues of strategic management. $\mathrm{He}$ suggests that National Health Service management (and he specifically defines this term as covering both the members of statutory authorities and their administrators) has lost its backbone. We realise, of course, that blaming all the ills of the National Health Service on to the administrator is a popular sport in some quarters, but in this case the allegation is so mistaken and unjust that it cannot go unchallenged.

Firstly, it seems that at the time when the article was published the General Whitley Council had not in fact concluded any agreement and it seems a little premature to castigate a body in respect of an agreement which it is thought that they might enter into. What is more relevant, however, is that administrators as such do not enjoy representation on the General Whitley Council and all persons serving on that body, whether members or officers, are nominees of the statutory health authorities.

My association steadfastly opposed the proposals for a national disputes procedure which were originally formulated by the previous Secretary of State and trade union representatives, on the grounds that any such scheme would detract from the authority 